\title{
¿POR QUÉ IMPORTA LA FILOSOFÍA EN LA UNIVERSIDAD Y EN LA CULTURA DE NUESTRO TIEMPO?
}

\author{
POR QUÉ IMPORTA LA FILOSOFÍA HOY ${ }^{1}$ \\ Carlos Peña \\ Universidad Diego Portales \\ carlos.pena@udp.cl
}

\begin{abstract}
$\overline{R A}$ Ante todo, muchísimas gracias por la invitación que me han cursado para intervenir en este encuentro y poder conversar con ustedes y, ojalá más tarde, discutir acerca de la importancia que reviste la filosofía en la cultura contemporánea.
\end{abstract}

Ahora bien, para dilucidar ese problema -el problema que hoy día nos reúneme parece fundamental formular dos preguntas que, si bien son distintas entre sí, se encuentran estrechamente enlazadas. Las dos preguntas que, en mi opinión, debiéramos hacer el esfuerzo de responder son las que siguen. En primer lugar, resulta imprescindible preguntarse -como lo hace este ensayo- por qué importa la filosofía, es decir, de dónde proviene el valor que indiscutiblemente -en especial sus cultores- le asignan a la filosofía, qué características reviste el quehacer filosófico que parecen hacerlo, a los ojos de quienes lo practican, imprescindible, inestimable, al extremo de que a veces se insinúa que si ella desapareciera, con ella se esfumaría también algo que estimamos muy importante. Así, pues, debemos reiterar la pregunta ¿por qué importa la filosofía?; hacer el esfuerzo de dilucidar, a la luz del propio quehacer filosófico, por qué ella podría ser tan relevante.

La segunda pregunta que acto seguido debiéramos intentar dilucidar -una vez que logremos precisar por qué la filosofía es importante desde el punto de vista puramente conceptual- es una pregunta de orden, ya no conceptual, sino más bien histórico y sociológico.

Se trata ahora de averiguar por qué, no obstante la importancia que el quehacer filosófico al parecer reviste-cuestión que habremos, como digo, identificado en la primera parte de esta exposición - la cultura contemporánea parece resistirse a la filosofía. En otras palabras, por qué si la filosofía nos parece tan importante y si conceptualmente podemos acreditar esa importancia, en la cultura contemporánea parecen hacerse esfuerzos permanentes y reiterados por desalojar a la filosofía prácticamente de todos los intersticios de la cultura pública, del sistema escolar, minusvalorarla incluso en la 
universidad, desalojarla del espacio público, como si se tratara de un quehacer inútil, prescindible, que distrae de lo que de veras importa, una especie de entretención casi ajedrecística de un grupo de personas, atractiva pero carente de importancia en realidad para la cultura pública.

Estas son, me parece, las dos preguntas que tenemos que dilucidar. No basta responder la primera; no basta que quienes cultivan la filosofía tengan razones para argüir en favor de la importancia de la filosofía, porque incluso si esas razones existieran, como yo creo que existen, cabe todavía preguntarse luego, acto seguido, por qué siendo tan importante la filosofía desde el punto de vista conceptual, la cultura contemporánea, como digo, se esmera en desalojarla de todas partes. Lo que diré en lo que sigue -muy brevemente desde luego, para que podamos luego discutir- es intentar responder la primera pregunta: por qué importa la filosofía. Y luego de hacerlo me detendré en la segunda: por qué, no obstante esa importancia, ella es tan poco reconocida en la cultura contemporánea. Este es mi plan de trabajo.

¿Por qué importa la filosofía? Para decirlo brevemente y anunciar la conclusión de lo que de inmediato diré: me parece a mí que puede afirmarse que la filosofía es, de todos los quehaceres intelectuales conocidos en la cultura contemporánea, el quehacer intelectual más radical, aquel que, como solía decir Jorge Millas, estira el pensamiento hasta el límite de sus posibilidades, o como prefiere Heidegger - el Heidegger de 1939se trata de un quehacer reflexivo hasta tal punto que intenta develar la misma estructura originaria que lo hace posible. La filosofía -digamos al principio una generalidad que luego precisaremos- es un quehacer que retrocede permanentemente hasta alcanzar, o pretender alcanzar, la estructura originaria que constituye la condición humana.

¿Cómo explicar esta índole radical que, al parecer, reviste la filosofía?

Me parece que un buen punto de partida para hacerlo es un texto de B. Russell, Filosofía del atomismo lógico, donde Russell formula una observación hasta cierto punto irónica y muy provocadora. En efecto, hacia el final de ese texto Russell afirma: "ciencia -dice- es lo que sabemos y filosofía es lo que no sabemos". De manera que Russell, en 1918, afirmó que conforme la ciencia se expandiera la filosofía comenzaría a ser desalojada de la cultura, porque ciencia era lo que sabíamos y filosofía era el nombre que dábamos a esas preguntas que la luz del conocimiento disponible eran insolubles, una forma disfrazada finalmente de nuestra ignorancia y de nuestra impotencia. Si la ciencia avanzaba la filosofía retrocedía -la ola de la ciencia, por decirlo así, estrechaba la playa de la filosofía- de suerte que, cuando la ciencia se desplegara en la plenitud de sus posibilidades, sugirió Russell en ese famoso texto, la filosofía no tendría espacio alguno en el ámbito de la cultura.

Cito a Russell, porque si uno revisa el estado de la filosofía y de la ciencia en la segunda mitad del siglo XIX, lo que observa es que, hasta cierto punto, la observación de Russell parecía cumplirse: la ciencia se había desplegado prácticamente en la totalidad de sus posibilidades en la segunda mitad del siglo XIX, y se planteó la pregunta, entonces, acerca de qué espacio le quedaba a la filosofía. Es la pregunta que Heidegger, como ustedes recuerdan, formula, a inicios del XX, en su famoso debate con Cassirer. La respuesta que dio la cultura europea de la segunda mitad del siglo 
XIX a esa pregunta fue que el lugar de la filosofía estaba no al lado de la ciencia, sino encima de la ciencia. Por encima de la ciencia, es decir, que la ciencia era un quehacer que se las veía de manera inmediata con la realidad, en tanto que la filosofía tenía más bien que ver con -como se dijo entonces reiteradamente-con el lenguaje de la ciencia o las posibilidades epistémicas de la ciencia. Por ejemplo, la respuesta al neokantismo fue exactamente esa: la filosofía no era desalojada por la ciencia, porque el quehacer de la filosofía consistía en acreditar las posibilidades de conocimiento que la ciencia desplegaba. Este fue la opinión del neokantismo, en general, durante toda la segunda mitad del siglo XIX. Y por otra parte, en el mundo anglosajón -y de esto participó Russell desde luego-, se dijo que la filosofía no es desalojada por la ciencia porque la filosofía se ocupa del lenguaje de la ciencia. Esta fue la respuesta que dio, como ustedes recuerdan, la filosofía analítica más tarde, y el positivismo lógico antes de ella.

En consecuencia, asumiendo el desafío de Russell, la filosofía se encontraba en la siguiente situación hacia fines del siglo XIX: no estaba al lado de la ciencia, ni estaba por debajo de la ciencia, sino que estaba por encima de ella, en la medida en que la filosofía acreditaba -como repito- las posibilidades cognitivas de la ciencia. Esta es la versión o la lectura que hace de Kant el neokantismo. O, en cambio, la filosofía se ocupa del lenguaje de la ciencia, es un metalenguaje de la ciencia, como ocurre con el positivismo lógico. Este es el panorama del quehacer filosófico a comienzos del XX y fines del XIX.

Lo que empieza, sin embargo, a ocurrir de manera paralela a este fenómeno que acabo recién de describir, es que la filosofía empieza a descubrirse a sí misma como un quehacer incluso más radical que esas dos formas que acabo de mencionar. Y eso ocurre, aunque parezca sorprendente, a partir de la obra de dos matemáticos. Y vale la pena hacer este apunte de la historia de la filosofía, para comprender las paradojas de la historia intelectual, porque hacia 1900, Husserl, como ustedes recuerdan, publica las Investigaciones lógicas; y antes de él, Frege pública Sentido y referencia, el famoso texto y antes de él había publicado los Fundamentos de la matemática, en 1884. ¿Por qué cito estos textos? Porque tanto Husserl como Frege -y esta es la paradoja de la historia intelectual- son matemáticos, pero no obstante ser matemáticos, son quienes ayudan a develar la índole radical de la filosofía, y lo hacen de la siguiente manera, que describo muy someramente ahora, a pesar de que no lo hago con el texto, desde luego.

Frege, en Sentido y referencia, como ustedes seguramente recuerdan, afirma que los seres humanos no nos las vemos inmediatamente con la realidad, sino que nos relacionamos con la realidad mediados por el significado. Esta es la afirmación fundamental que hace en Sentido y referencia. Tanto los nombres propios, como "Homero", o las descripciones definidas, como "el autor de la Odisea", ustedes recuerdan, nos acercan a la realidad, pero mediando nuestro trato con la realidad a través del significado y, en consecuencia, dijo Frege, lo que cabe preguntarse es de dónde proviene el significado, que es la pregunta que se había hecho en 1884, en Los fundamentos de la aritmética, cuando se preguntó qué es un número. Y lo que dijo Frege fue, para decirlo someramente, que el significado no estaba ni en la cabeza, es decir no era una experiencia psicológica -que es la misma afirmación que va a hacer más tarde Husserl- ni tampoco está en las cosas, de manera que cuando digo "creo 
que hay tres vasos sobre esta mesa" el número tres no está en las cosas que miento en ese enunciado, ni en la subjetividad que poseo al pronunciarlo, sino que, dijo Frege, en realidad el significado está en un fenómeno cultural muy notable -que la filosofía había abandonado, a pesar de que Aristóteles, en su origen, había hecho esfuerzos por ocuparse de esto en la Retórica-, que es el lenguaje. Y el lenguaje es un evento público qué exorbita a cada individuo humano, que lo excede, pero que nos permite constituirnos finalmente en una especie de diálogo sin fin, que llamamos cultura. De suerte que el significado y el sentido - esa es la afirmación de Frege y de Husserl - está en el lenguaje, está fuera del sujeto. Menciono esto porque este es -el propio Heidegger creo yo en su propio quehacer y desarrollo filosófico lo acredita- el punto de partida de la crisis de lo que podríamos llamar la "filosofía de la conciencia", la idea de "sujeto" moderno, la idea de que el mundo está estructurado, tiene su garantía en una "ciudadela interna" que estaría dentro de cada uno de nosotros, que llamaremos subjetividad, conciencia, y que, en consecuencia, la única garantía que tenemos de nuestro razonamiento práctico y teórico está, como digo, ensimismándonos, que es la afirmación que desde Descartes había iluminado, digámoslo así, a la cultura occidental.

Pero lo que hacen Frege y Husserl es iniciar un camino, que se ha radicalizado en la cultura contemporánea, y que es la crisis del sujeto, la crisis de esta filosofía de la conciencia, porque, a contar de allí -y aunque suene sorprendente-, la filosofía se encaminó -ahora sí- a la pregunta más radical de todas, y es la siguiente: si la experiencia de ser un sujeto se constituye desde fuera de sí mismo, puesto que, como había dicho Frege, estamos volcados en el lenguaje, si estamos, por decirlo así, trascendidos en nuestra propia subjetividad, si somos "ex-sistentes", o sea, sujetos vertidos fuera de nosotros, por decirlo así, la pregunta que entonces la filosofía tiene que plantearse es ¿cuál es la índole de ese ámbito en el cual el sujeto se constituye, ese ámbito donde lo que somos está inevitablemente entrelazado con lo que no somos?

Este es el sentido de la reflexión que Heidegger desde luego inaugura, pero no es el único, que consiste en formular la pregunta ¿en qué consiste ese ahí en el que nos verificamos como experiencia, ese ahí que no está en la conciencia, que no es posible alcanzar ensimismándonos, sino que más bien es posible comprenderlo por la vía de describir la facticidad de la existencia, esa facticidad que consiste en estar volcado, estar extravertido en las cosas, en vez de estar recluidos en una ciudadela interna desde la que, de pronto, saldríamos como a cazar las cosas, como se describió el conocimiento hasta bien entrado el siglo XX, esa idea de que usted en realidad era una ciudadela interna donde estaba la garantía del conocimiento, desde la que de pronto salía a atrapar las cosas, volvía a esta ciudadela y lograba, entonces, acreditar que era verdadero, o que, en cambio, debía rechazarse como falso? Nada de esa imagen, como digo, es propio de la reflexión filosófica que a partir del momento que acabo recién de mencionar se desata. Entonces - esto lo que yo pienso- tanto Heidegger (desde luego el Heidegger de 1918 a 1936 fundamentalmente), como Ortega en el mundo hispano, como Wittgenstein (particularmente el segundo Wittgenstein) erigen su concepción de la filosofía y describen la índole del quehacer reflexivo sobre la base de reflexionar la estructura originaria que hace que seamos entes enlazados indisolublemente con el mundo. 
De suerte que, en vez de asumir Heidegger, Wittgenstein y Ortega que la constitución básica de la que se ocupa la filosofía es la relación entre un sujeto previamente constituido con una conciencia quiescente y cerrada sobre sí misma, y un mundo externo, que es como, en general, se había presentado el problema de la filosofía o el conocimiento, que agotaba casi la agenda de la filosofía a fines del XIX, en vez de pensar así, lo que estos autores intentan hacer es < preguntarse $>$ ¿cuál es esa estructura originaria que hace posible que el ser humano sea un sujeto que teje redes interpretativas hasta originar una malla interpretativa de toda la realidad, que es lo que llamamos mundo, una de cuyas versiones es esta idea de un sujeto enfrente de un mundo quiescente que está a su disposición? En otras palabras, tanto Wittgenstein -por ejemplo, en Sobre la certeza, para no citar el conocido Investigaciones filosóficas-, como Ortega y -para qué decir-Heidegger se ocupan exactamente de este problema: ¿cuál es la estructura originaria que antecede a toda experiencia posible, pero no en el sentido del problema epistemológico, sino en el sentido del problema más bien ontológico? ¿cuál es esta estructura originaria que nos hace estar entreverados con las cosas, pero al mismo tiempo tener la experiencia de infinita distancia respecto de ellas, que es lo que Heidegger llama diferencia ontológica?

Jamás la filosofía había alcanzado una radicalidad como ésta que acabo recién de describir, que continúa Ortega -continúa o anticipa: Ortega siempre sugirió que lo había anticipado en realidad, no lo había continuado simplemente, pero ese es un debate que podemos dejar pendiente- pero la cuestión es: la filosofía, como consecuencia de este transcurso que acabo recién de describir (en términos muy gruesos por supuesto, luego podemos agregar más detalles) alcanza una radicalidad y una conciencia de esa radicalidad que nunca había tenido, la idea, repito, de que el sujeto humano-las palabras son totalmente inadecuadas- aquello que somos lo somos entreverados con las cosas, pero sin poder nunca abandonar la infinita distancia que tenemos respecto de ellas $\mathrm{y}$, en consecuencia, la condición humana como estructurada en torno a una especie de herida, que Heidegger llama diferencia ontológica, entre el mundo que tenemos en derredor y del que no podemos sacudirnos, puesto que es como una sombra que nos acompaña, sobre la que nuestra condición se yergue, y da origen a una pregunta fundamental que nos asalta y que no podemos eludir: ¿en qué consiste esta diferencia que nos constituye?

Esta es la pregunta de Leibniz, por supuesto, “¿por qué hay algo y no más bien nada?", que retoma más tarde Heidegger. Pero a mí lo que me interesa subrayar es, por decirlo así, la cuestión cultural que instala esta forma de concebir la filosofía y que es posible detectar - pero luego podemos discutir esto- no solo desde luego en la filosofía como disciplina. Buena parte de la cultura contemporánea, inspirada en este tipo de reflexiones, subraya exactamente lo mismo: para qué decir el psicoanálisis con Lacan, por citar un caso clásico. De manera que ¿por qué importa la filosofía? es una pregunta que, si uno repara en la índole de la reflexión filosófica tal como ella se constituye en los inicios de 1920 y como consecuencia de ese momento de filosofía de las matemáticas que acabamos de describir, si uno atiende a ese momento y se pregunta por qué importa la filosofía, la respuesta parece clara: la filosofía importa porque es el único esfuerzo intelectual que es posible advertir en la cultura humana que intenta develar la estructura originaria que nos permite que exista algo así como cultura, pero que al mismo tiempo nos revela que eso que llamamos cultura es un 
disfraz de la realidad, un disfraz contingente, que en cualquier momento la realidad puede sacudirse fuera de sí. Esta es la afirmación central, creo yo, que uno encuentra en Wittgenstein, que uno encuentra en Heidegger, que uno encuentra en Ortega. Por supuesto, uno la encuentra también en el resto de la filosofía continental; a mí me parece que autores como Habermas, Luhman -por citar dos que están en las fronteras de la filosofía y la sociología-, también ellos ciertamente se encaminan por esta línea y no es casualidad que Habermas, que Luhmann, tengan como una de sus influencias a Husserl, y también a Heidegger.

Pues bien, dilucidado por qué importa la filosofía a la luz del propio quehacer filosófico, no hemos respondido todavía otra cuestión fundamental. Si la filosofía es tan importante, tan relevante como acabamos de mostrar ¿por qué la cultura contemporánea parece alérgica a ella?, ¿por qué se empeña en desalojarla de todas partes? ¿porque los filósofos son sujetos a quienes la cultura contemporánea del éxito mira con inocultable desprecio, como si la filosofía fuera un quehacer menor, una entretención de personas incapaces para la vida, digamos, una racionalización de personas, finalmente, a las que habita un cierto fracaso inconfesado? ¿Por qué la cultura contemporánea mira de esta manera a la filosofía, si -como acabamos de ver- es el esfuerzo más radical que la cultura ha generado para comprenderse a sí misma? Esta es la segunda pregunta que querría responder, y a mí me parece que la propia filosofía ayuda a hacerlo.

En efecto, Heidegger - pero no solo Heidegger, sino que también Weber- ha intentado responder esta pregunta. Y es que la modernidad, a la que podríamos describir largamente del punto de vista sociológico - haciendo pie en el concepto de racionalización de la vida- desde el punto de vista de la filosofía es una época que, por decirlo así, ha olvidado la pregunta por el sentido. Schelling lo dijo de forma inmejorable: se trata de un mundo en que los dioses han huido. Así lo diría, si uno se pregunta o le pregunta a la obra de Max Weber “¿qué es la modernidad”? Weber, el gran sociólogo alemán, dejaría de lado todas las caracterizaciones que vienen de Durkheim, digamos, y de la sociología clásica, y diría, como lo dice en las últimas páginas de La ética protestante y el espíritu del capitalismo: la modernidad es una época que surgió adoptando un punto de vista respecto del sentido de lo que existe, y que más tarde olvidó esa pregunta y la respuesta que había formulado, hasta empezar a girar performativamente sobre sí misma, hasta encerrarse, para repetir la fórmula famosa, en una "jaula de hierro".

La modernidad como una jaula de hierro: esta famosa figura, esta famosa metáfora, lo que subraya esa modernidad como una época que surgió de la mano con la cuestión del sentido - por eso Weber se ocupó tanto de la sociología de la religión, a fin de dilucidar lo propio de la edad moderna-, pero acabó olvidando la pregunta que la había desatado y, por supuesto, descuidando totalmente la respuesta hasta transformarse en una época, como digo, que se justifica performativamente a sí misma. Esto lo dice explícitamente en las últimas páginas de La ética protestante. "Performativamente", es decir, la mera ejecución de sus operaciones constituye la fuente de legitimidad de esas mismas operaciones. Vanidad de vanidades, como suele decir Weber, citando al Eclesiastés.

Esto que parece sociología es exactamente lo que Heidegger había dicho, piensen ustedes, en 1936, en un famoso curso sobre Introducción a la metafísica. Heidegger 
había dejado el rectorado -se había desilusionado de ese coqueteo infame que tuvo con el nazismo-, escribe Introducción a la metafísica, y allí pertenece ese famoso párrafo, que ustedes recuerdan, donde Heidegger prácticamente anticipa nuestro tiempo, poniendo de relieve hasta qué punto nuestro tiempo, la modernidad, es un tiempo que procura olvidar la pregunta por el sentido sin nunca lograrlo. El párrafo, que cito de memoria de manera que puede haber algún defecto menor, es más o menos el siguiente: cuando un suceso cualquiera, dice Heidegger, pueda ser experimentado en un tiempo cualquiera y en un lugar cualquiera, cuando el globo sea técnicamente conquistado y económicamente explotado, cuando podamos simultáneamente experimentar el atentado a un rey en Francia o un concierto en Tokio, cuando el tiempo sea simultaneidad e instantaneidad y la experiencia temporal, dice él, como historicidad haya desaparecido de la faz de la tierra, cuando el boxeador-podríamos decir cuando el payaso-rija como el gran hombre de una nación y en número de millones triunfen las masas reunidas en asambleas populares, entonces, justamente entonces -concluye en este párrafo famoso- cruzarán todo este aquelarre como fantasmas las preguntas ¿para qué? ¿hacia dónde? ¿después qué?

Es decir, la pregunta por el sentido es la pregunta que, en opinión de Heidegger, desata la diferencia ontológica. La pregunta por el sentido es la gran pregunta que entrecruza la modernidad, pero la modernidad se resiste a reconocerla como pregunta y, como se resiste a reconocerla como pregunta, se trata, en opinión de Heidegger, de una época que él va a llamar la época técnica o la época de la imagen del mundo, una época donde todo se mide por el rasero de la utilidad inmediata, por el servicio que presta a algún propósito o designio humano. Y parece evidente que la filosofía, de la manera que antes la describíamos, no sirve a ninguno de esos propósitos, porque pone en cuestión todos los propósitos. O sea, la filosofía, diría Heidegger, está desalojada del mundo moderno, porque el mundo moderno es un mundo hipnotizado, hechizado por la técnica, por la idea que todo lo existente es un algo puesto a disposición de un propósito, y como la filosofía lo que hace es mostrar la futilidad contingente de todo propósito, porque se esmera en demostrar la estructura originaria que hace posible plantearse propósitos, entonces la filosofía es desalojada de este mundo de la técnica, del mundo de la modernidad, del mundo de la época de la imagen del mundo; o sea, de aquel momento histórico donde el mundo es concebido como imagen -esto es lo que dice Heidegger ya en los años cincuenta.

Como la filosofía tiene esa radicalidad, acaba siendo entonces desalojada $-\mathrm{O}$ queriendo desalojarla- del mundo contemporáneo, porque ella no tiene un espacio en este mundo de útiles, en este mundo de existencias puestas al servicio de propósitos humanos, porque la filosofía es aquel momento de duda radical, que pone en cuestión toda la cultura. Porque la filosofía es como dije antes -y con esto termino- aquel tipo de reflexión tan radical que devela la estructura originaria que hace posible que exista algo así como cultura, o sea esta red de interpretaciones que llamamos cultura, mostrando al mismo tiempo, que ella no es más que un disfraz de una realidad que finalmente es inasible, la interpretación de un original que nos será siempre negado. Esta, creo yo, es la particularidad de la filosofía y, al mismo tiempo, la razón de por qué ella aparece hoy día a nuestros ojos como inútil. 